\title{
Erde und Leben
}


Norbert Welsch · Claus Chr. Liebmann · Jürgen Schwab

\section{Erde und Leben}

Die Geschichte einer innigen Wechselbeziehung

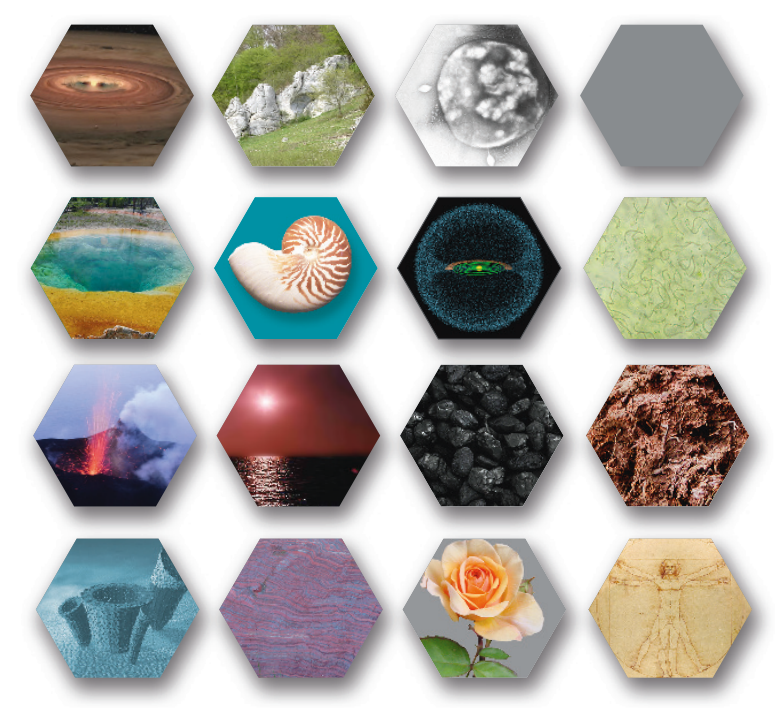

包 Springer 


\section{Dr. Norbert Welsch}

(verstorben)
Jürgen Schwab

Schellingstr. 47

72072 Tübingen

juergenm.schwab@matter-matters.de

Dr. Claus Chr. Liebmann

Marbachstr. 1

81369 München

ISBN 978-3-662-53868-5

ISBN 978-3-662-53869-2 (eBook)

DOI 10.1007/978-3-662-53869-2

Die Deutsche Nationalbibliothek verzeichnet diese Publikation in der Deutschen Nationalbibliografie; detaillierte bibliografische Daten sind im Internet über http://dnb.d-nb.de abrufbar.

C Springer-Verlag GmbH Deutschland 2017

Das Werk einschließlich aller seiner Teile ist urheberrechtlich geschützt. Jede Verwertung, die nicht ausdrücklich vom Urheberrechtsgesetz zugelassen ist, bedarf der vorherigen Zustimmung des Verlags. Das gilt insbesondere für Vervielfältigungen, Bearbeitungen, Übersetzungen, Mikroverfilmungen und die Einspeicherung und Verarbeitung in elektronischen Systemen.

Die Wiedergabe von Gebrauchsnamen, Handelsnamen, Warenbezeichnungen usw. in diesem Werk berechtigt auch ohne besondere Kennzeichnung nicht zu der Annahme, dass solche Namen im Sinne der Warenzeichen- und MarkenschutzGesetzgebung als frei zu betrachten wären und daher von jedermann benutzt werden dürften.

Der Verlag, die Autoren und die Herausgeber gehen davon aus, dass die Angaben und Informationen in diesem Werk zum Zeitpunkt der Veröffentlichung vollständig und korrekt sind. Weder der Verlag, noch die Autoren oder die Herausgeber übernehmen, ausdrücklich oder implizit, Gewähr für den Inhalt des Werkes, etwaige Fehler oder Äußerungen. Der Verlag bleibt im Hinblick auf geografische Zuordnungen und Gebietsbezeichnungen in veröffentlichten Karten und Institutionsadressen neutral.

Planung: Frank Wigger, Dr. Christoph Iven

Einbandabbildung und -entwurf: Welsch \& Partner - scientific multimedia, Tübingen

Satz: Welsch \& Partner scientific multimedia, Tübingen und Jürgen Schwab, Tübingen

Gedruckt auf säurefreiem und chlorfrei gebleichtem Papier

Springer ist Teil von Springer Nature

Die eingetragene Gesellschaft ist Springer-Verlag GmbH Deutschland

Die Anschrift der Gesellschaft ist: Heidelberger Platz 3, 14197 Berlin, Germany 


\title{
Für \\ Laura-Marie und Lorraine
}

Norbert Welsch

\author{
Für
}

Anni Liebmann

Claus Chr. Liebmann

\section{Für \\ Ursula Dachs und Heinz Schwab}

Jürgen Schwab 


\section{Danksagung und Nachruf}

Wir danken allen Familienmitgliedern, Freunden und Bekannten, die im Laufe der vier Jahre der Entstehungszeit durch Diskussionen, Hinweise, Beiträge, Bereitstellung von Bildern und Korrekturen aktiv am Zustandekommen des Buches beteiligt waren oder die einfach unter der zeitlichen Konkurrenz zu leiden hatten. „Vita brevis, ars longa“ gilt leider auch für die Arbeit an einem Werk, das allen drei Autoren viel Herzblut abverlangt hat.

Last but not least ist der Verlag ein entscheidender Faktor beim erfolgreichen Zustandekommen eines Buchwerkes. Wir danken hier insbesondere Frau Sabine Bartels und Herrn Frank Wigger sowie in der Konzeptionsphase noch Herrn Dr. Christoph Iven für die engagierte redaktionelle Betreuung über die ganzen Entstehungsjahre. Hier konnten wir auf ein kompetentes und wohlwollendes Team bei Springer-Spektrum zählen, das uns einerseits durch Terminvorgaben eine realistische Grenze zog (und diese mehrfach leider erweitern musste), andererseits aber auch stets ein offenes Ohr bot und Lösungen für anstehende Probleme bereit hatte. Auch möchten wir uns bei Frau Behncke-Braunbeck bedanken, die uns bereits über viele Jahre und Bücher hinweg auf Seiten des Verlages begleitet und unterstützt hat.

Norbert Welsch

Jürgen Schwab

Claus Chr. Liebmann

Völlig unerwartet verstarb Norbert Welsch kurz vor Fertigstellung dieses Buches.

Wir verloren nicht nur einen langjährigen Kollegen, sondern auch einen teuren Freund. Seine unstillbare Neugier darauf, wie die Welt im kleinsten und im größten „funktioniert“, war nicht nur ansteckend, sondern Voraussetzung dafür, dass derart umfassende Werke wie „Materie“ und „Erde und Leben “ überhaupt entstehen konnten. Bei Norbert Welsch war diese Neugier gepaart mit sprühender Intelligenz und der Fähigkeit, Naturwissenschaft in verständlicher und humorvoller Form darzustellen. Die Arbeit mit ihm war immer spannend und anregend, selten trafen wir einen Menschen mit einem solch breiten Wissen und dem Willen, es zu teilen. Wir werden ihn sehr vermissen.

Jürgen Schwab

Claus Chr. Liebmann 


\section{Vorwort}

Man kann sich zu Recht fragen, wozu man noch ein weiteres Buch benötigt, das die Entstehungsgeschichte der Erde und des Lebens thematisiert. Darüber wird seit den Zeiten eines IMMANUEL KaNT und CHARLES DARWIN von exzellenten Forschern spekuliert, geforscht, modelliert und publiziert. Heute existiert eine mit der Intensität der Forschung und der Schnelllebigkeit unserer Zeit immer rapider zunehmende, kaum noch überschaubare Flut von Fachartikeln. Wie aus der Literaturliste am Ende des Buches ersichtlich, gibt es zahlreiche ausgezeichnete populärwissenschaftliche Werke, die die Geschichte unserer Herkunft erzählen und einer breiteren Leserschaft zugänglich machen. Daneben sind praktisch alle neuen Erkenntnisse für den aufmerksamen Benutzer in entsprechenden Internet-Foren und Wikipedia-Artikeln zu finden.

Ein Grund für neue Bücher ist natürlich, ein Resümee zu ziehen über den jeweils aktuellen Forschungsstand, der oft genug altbekannte Tatsachen in ein anderes Licht rückt. Heute ist Wissenschaft so weit spezialisiert, haben sich so viele kleine abgegrenzte Forschungsgebiete mit jeweils eigenen Fachjournalen und eigener Fachsprache entwickelt, dass selbst ausgewiesene Wissenschaftler oft in Nachbardisziplinen nicht viel mehr sind als Laien. Auch für sie ist es nützlich, gelegentlich über den Tellerrand ihrer jeweiligen Disziplin hinauszuschauen. Wir glauben, dass es zum Prozess einer öffentlichen Wissenschaft gehört, anerkannte Theorien und neueste Erkenntnisse zusammenzubringen und die Geschichten - in diesem Fall die der Erde und des Lebens - aus verschiedenen Blickwinkeln immer wieder neu zu erzählen.

Betrachten wir die vielfach bestätigte Evolutionstheorie DARWINs. Betrachten wir die komplexen biochemischen Abläufe in einer Zelle, die wir vielfach kennen und gezielt beeinflussen können. Und betrachten wir die Vorgänge der DNA-Duplikation und der Biosynthese von Eiweißen, die wir inzwischen so gut beherrschen, dass wir sie im Rahmen moderner Molekularbiologie routinemäßig und in industriellem Maßstab manipulieren. Könnte man da nicht der Ansicht sein, wir hätten das Wesentliche am Leben längst verstanden?

Weit gefehlt! Es ist ein gigantisches Projekt, dem sich Biologen, Geologen, Chemiker, Paläontologen und Wissenschaftler zahlreicher anderer Disziplinen verschrieben haben, die sich an der Erforschung der Entstehungsgeschichte unserer Lebewelt versuchen. Schauen wir uns die Lebensvorgänge nur etwas genauer an, so mag man leicht verzweifeln ob der Größe der Aufgabe. In einer Zelle laufen abertausende chemische Reaktionen parallel ab, sind in einem sich selbst erhaltenden und gegenseitig regulierenden System verwoben, dessen Komplexität wir heute erst erahnen.

Woher weiß jeder Teil des Zytoskeletts, in welche Richtung er expandieren muss, woher jedes Motorprotein, wohin es dieses oder jenes Organell zu transportieren hat? Wie wird verhindert, dass ein so delikat verschränktes Netzwerk chemischer Reaktionen, wie es eine lebende Zelle darstellt, unwiderruflich im Chaos versinkt? Trotz aller naturwissenschaftlichen Nüchternheit und fern davon, irgendwelchen kreationistischen Ideen und Scheinlösungen das Wort zu reden, steht man doch mit einem Schaudern vor dieser ungeheuren Komplexität und Vielfalt. Noch mehr als der oberflächliche Blick auf das Verhalten eines ganzen Organismus lässt uns die wissenschaftliche Analyse der Strukturen und Mechanismen staunen, die in der Evolution des Lebens auf unserem Planeten und in enger Interaktion mit diesem entstanden sind.

Wir wissen nicht, wie lange der Weg zu einem echten Verständnis dieser Prozesse und Strukturen noch ist und wie viele Generationen von Forschern sie noch beschäftigen werden. Ja, wir wissen nicht einmal, ob es uns jemals gelingt herauszufinden, wie das Leben auf unserem Planeten begann. Denn dies war vermutlich ein historisch einmaliger Vorgang, von dem, wenn überhaupt, nur sehr indirekte Spuren geblieben sind. Aber jeder Weg beginnt mit dem ersten Schritt - und einige Schritte sind wir schon gegangen. Sie sollen das Thema unseres neuen Buches sein.

\footnotetext{
Norbert Welsch

Jürgen Schwab

Claus Chr. Liebmann
} 


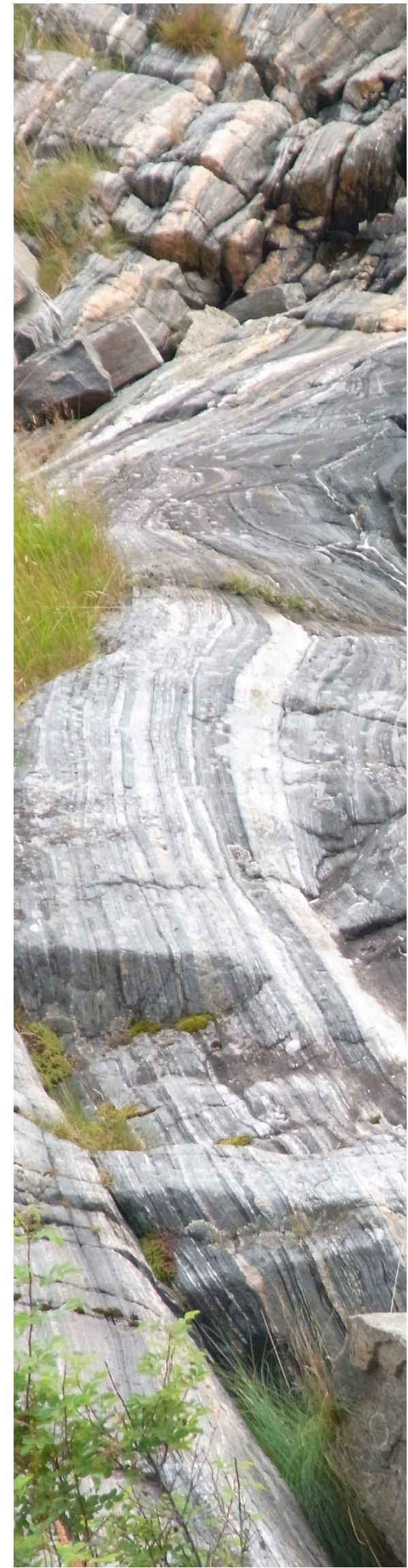

VIII
Von der Erde

In einem Raum

den nie ein Auge sah

kam sie schon vor uns an

die Dienerin des Lebens

sie hat sich vor uns aufgemacht

auf einen langen Weg

ohne Unterschied

zwischen Tag und Nacht

Sie sollte ibre Reise nicht alleine tun

denn plötzlich war das Leben da erst noch zaghaft ging

es über ihre Haut

ganz zärtlich sanft und leise

mit kleinen Füßchen

hört es nicht auf

$z$ laufen und bewußt zu sein

und nicht lange auszurub'n

Den Weg zum Dasein fanden wir von ihr stets wohl begleitet in ihr, der Dienerin des Lebens, des Wachstums und des Gebens ein Wunder vorbereitet

Wenn irgendwann ein Leben geht um Neuem Platz zu machen

so soll es sein

dass sie uns dann

wie eine große Mutter

in ibre Arme nehmen kann

Dass sie

in unvorstellbar langer Fabrt

Spuren des Lichts

Spuren des Lebens

in ihrem Körper aufbewahrt.

Klaus Wermke 


\section{Inhalt}

\section{Biogeologie}

Eine Wissenschaft der Wechselwirkungen

Gaia kehrt zurück 3

Vom Entstehen und vom Sein

Der stete Lauf der Welt 5

Lebewesen und ihre Umwelt 5

Auf der Suche nach LUCA 8

Im Dunkel der Vergangenheit 9

Was Sie in diesem Buch erwartet

Überblick 10

\section{Geodetektive}

\section{Was uns die Steine erzählen}

Das offene Buch der Geologen 15

Stratigraphie - Schicht für Schicht 15

Gestalt und Tiefenbau der Erde 21

Plattentektonik 23

\section{Methoden der Spurensuche}

Geochemische Analysen und Instrumente

Instrumentelle Analytik

\section{Isotope}

Nicht alle sind gleich $\quad 28$

Isotopenuhren 29

Optische Lumineszenzdatierung 32

\section{Biomarker}

Gut konserviert 32

\section{Spuren der Evolution}

\section{Darwins Geniestreich}

Entdeckung der Geschichte der Lebewelt

Ähnlichkeiten lebender Formen 39

On the Origin of Species 40

Fossile Überlieferung 41 


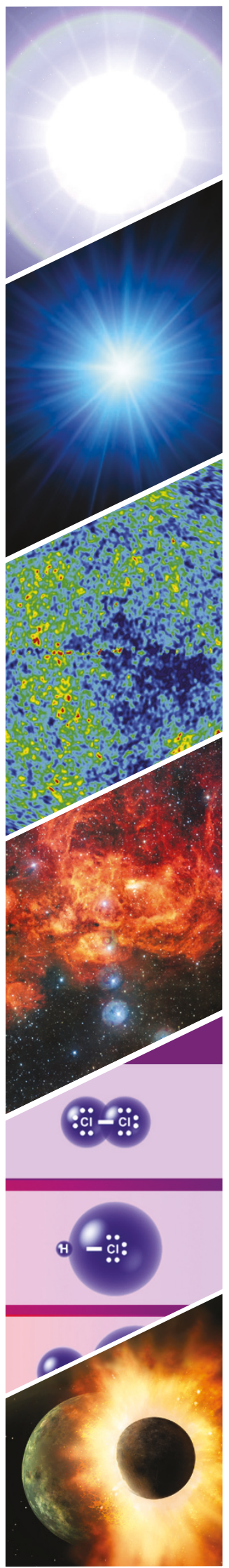

\section{Biochemie heute}

Des Chemikers Albtraum 42

Zentrale Biomoleküle 43

\section{Das Archiv in uns}

Zellbestandteile erinnern sich

Molekulare Uhren 50

Mutationsraten 50

Untersuchung ribosomaler DNA 51

Mitochondriale DNA 51

Zellkern-DNA 52

\section{Rekonstruktionen}

Eröffnung des Jurassic Park? 52

Rekonstruktion von DNA-Sequenzen 52

Rekonstruktion und Untersuchung von Proteinsequenzen 53

\section{Die kosmische Bühne}

\section{Wie alles begann...}

Im Anfang war das Licht 57

Der Samen der Welt 57

Atome und Sterne entstehen

\section{Planeten - aus Staub geformt}

Aus Staubwolken werden Scheiben

Von Scheiben zu Planeten 61

Steine und Eiskugeln 63

Monde 64

Vom Ende des Sonnensystems 67

\section{Kosmisches Labor}

Chemie im kalten Universum 68

Das interstellare Medium 68

Lebensmoleküle aus dem All 69

\section{Die Urerde}

\section{Abenteuer eines jungen Planeten}

Es begann vor 4,5672 Milliarden Jahren 73

Gaias Tochter bringt uns den Mond 73

Vom Glutofen zum Tropenklima 74

Woher stammt das Wasser? 77

Late Heavy Bombardement - Ein Tanz mit Folgen 78 
Kontinente entstehen

Bewegliche Kruste 79

Einsetzen der Plattentektonik 81

Kosmische Einflüsse

Von Zyklen und Katastrophen

84

Kosmische Katastrophen 86

Kosmische Strahlung 87

\section{Chemische Evolution}

Das Leben verstehen

Aufbruch und Stolpersteine 91

Leben - was ist das? 92

Energie und Entropie - offene Systeme

92

\section{Elemente des Lebens}

CHNOPS - Die richtigen Stoffe sind zur Stelle 96

Erste Schritte zum Leben 99

Herkunft organischer Moleküle 101

Wo lag Darwins Tümpel? 103

Molekülsynthese ohne Chemiker

Die Ursuppe ist dünn geworden...

105

Replikation oder Stoffwechsel zuerst? - Die Sache mit der Henne und dem Ei 107

Replikator und Hyperzyklus - Fehlerexplosion und Familienbande 110

\section{Vergangene Welten?}

Hypothesen und Experimente 112

Eisen-Schwefel-Welt (ESW) 112

Welt der alkalischen Schlote 114

Aminosäuren und Protein-Welt 114

Nukleotide und RNA-Welt 116

Exotische Vorgänger-Welten

121

\section{Erste Zellen}

Protobionten, Progenoten - Urzellen

Der genetische Code in einer Protein-tRNA-Welt

124

Übergang zur heutigen DNA-RNA-Protein-Welt

Zurück zu LUCA 127
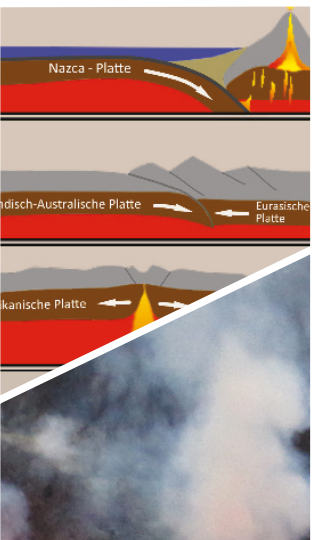


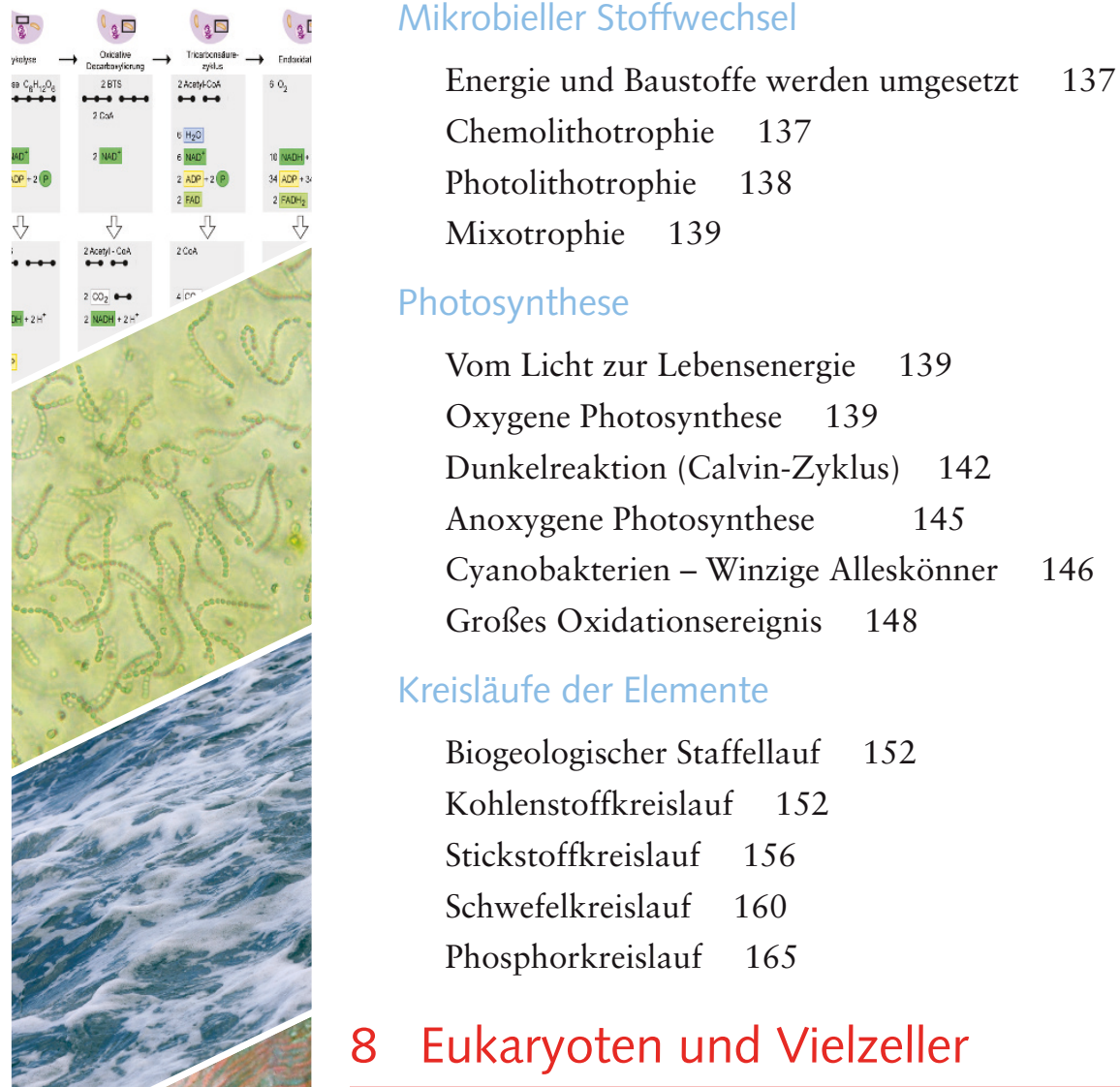

Eukaryoten

Kerne und Membranen 173

Vom Einfachen zum Komplexen

Zelluläre Evolutionsschritte 173

Evolution prokaryotischer Zellen 174

Endosymbiontentheorie 176

Auf dem Weg zu Vielzellern

Bizarre tierische Lebensformen, Pilze und Urvielzeller 179

Urtierchen und Schwämme 179

Ediacara-Fauna 181

Darwins Dilemma

Tiere aus dem Nichts!? 184

Kambrische Innovationen 184

Genregulationsnetzwerke 186

Pilze

Ein Leben im Verborgenen 188 
Der grüne Schleier des Landes

Landpflanzen und Ökologie 191

Schrittmacher der Evolution 191

Bedeutung der Pflanzen 196

Massenaussterbeereignisse

Wenn die Erde krank wird 197

Massensterben im Perm 200

\section{Atmosphäre und Ozeane}

\section{Zwei Untrennbare}

Ein reger Austausch 207

Wechselwirkungen 207

Von der Höllenglut zur Atemluft

Drei Atmosphären 211

Die Atmosphäre im Präkambrium 211

Die Atmosphäre im Phanerozoikum 214

\section{System Erde}

Von Gaia und Gänseblümchen 217

Daisyworld-Modell 221

Claw-Hypothese 222

Canfield-Ozean 224

\section{Schneeball-Erde}

Das Überleben auf einem Eisplaneten

Proterozoische Vereisungen 225

\section{Gebirge aus Organismen}

\section{Evolution der Minerale}

Schritte zu einem komplexen Planeten

Biomineralisation/Biominerale 237

Erste Riffe, die Stromatolithe 239

\section{Bändereisenerze}

Rohstoffe aus dem Präkambrium 241

Kalkgesteine

Baumaterial biogener Gebirge 244

Städte unter Wasser 247

Kohle

Eingefangenes Kohlendioxid 250 


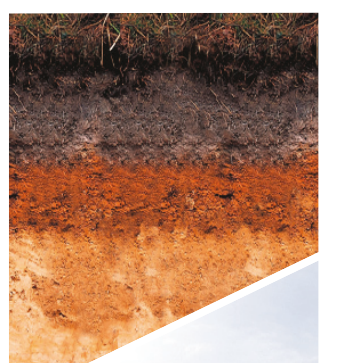

\section{Kerogene}

Erbe vergangenen Lebens 254

Bildung und Reifung 254

Chemische Zusammensetzung 255

Erdöl- und Erdgas-Lagerstätten 257

\section{Leben drunter und drüber}

Die verletzliche Lebenshaut der Erde

Was ist eigentlich „Boden“? 263

Bodenbildungsprozesse 265

Bodenhorizonte 269

Bodenwasser 271

Wundererde aus dem Amazonas-Becken 272

Paläoböden

Zeugen früherer Umweltverhältnisse 275

\section{Einfluss des Menschen}

Der Ast, auf dem wir sitzen

Der Mensch als geologischer Faktor

279

Macht euch die Erde untertan 281

Vom Winde verweht 288

Wühlmäuse 289

Klimawandel 293

Universalwerkzeug Nervensystem

Zwei Systeme am Werk 300

Die Evolution des Gehirns 301

Was uns zu Menschen macht 303

Evolution der Zukunft

Wohin die Reise geht... 311

Geht die menschliche Evolution weiter? 312

Mensch $2.0 \quad 314$

\section{Anhang}

Literaturverzeichnis 324

Stichwortverzeichnis 326 